\title{
The Mutual Correlation of Glucose, Starch, and Beta-Glucan Release During Microwave Heating and Antioxidant Activity of Oat Water Extracts
}

\author{
Joanna Harasym ${ }^{1,2} \cdot$ Remigiusz Olędzki $^{2}$
}

Received: 21 October 2017 / Accepted: 17 January 2018 / Published online: 27 January 2018

(C) The Author(s) 2018. This article is an open access publication

\begin{abstract}
Starch and beta-glucan are most abundant carbohydrate polymers available in oat products; however, their simultaneous release during extraction depends on morphological and processing conditions of raw material. The study analyzes the mutual correlation between the sample (oat flakes and bran) and treatment types (microwave heating (MW) $-1-5$ min; conventional heating $(\mathrm{CH})-7 \mathrm{~min}$ ) on water extract properties focusing on beta-glucan, starch, and glucose content as well as the antioxidant activity of water extracts. The strong negative partial coefficient correlation was found between solids-starch $(-0.65)$ and starch-glucose $(-0.89)$ content as well as DPPH $(-0.66)$ antioxidant activity in oat flakes revealing the high release of glucose to the water phase and its prooxidant activity. For the oat bran, positive and very high partial coefficient was found for both glucose $(0.98)$ and beta-glucan (0.98) content in solids while the mutual interaction between them was highly negative $(-0.97)$, meaning the more beta-glucan, the less glucose in the water phase.
\end{abstract}

Keywords Beta-glucan $\cdot$ Starch $\cdot$ Glucose $\cdot$ Antioxidant activity $\cdot$ Microwave $\cdot$ Oat

\section{Introduction}

The undisputable bioactivity of oats had already met the wide scientific interest leading to EFSA (European Food Safety Authority, European Union) and FDA (Food and Drug Administration, USA) health claim issue which confirmed the oat beta-glucan impact on lipid and glucose metabolism, but also appreciated the beneficial effects of the whole oat fiber for gut health (EFSA Panel on Dietetic Products 2011; European Food Safety Authority (EFSA) 2010, 2011). As the

Joanna Harasym

joanna.harasym@ue.wroc.pl; joanna.harasym@gmail.com

Remigiusz Olędzki

remigiusz.oledzki@ue.wroc.pl

1 Bio-Ref Laboratory, Department of Biotechnology and Food Analysis, Wrocław University of Economics, Komadorska 118/120, 53-345 Wrocław, Poland

2 Department of Biotechnology and Food Analysis, Wrocław University of Economics, Komadorska 118/120, 53-345 Wrocław, Poland gastrointestinal tract is one of the main entrances for possible harmful substances entering a human system, therefore, its homeostasis is the second fundamental purpose of eating beyond nutrition. Several lastly published research has highlighted bioactivity of oat beta-glucan which exceeds only the mechanistic role of the viscous film, formed in the gastrointestinal tract, and revealed strong metabolic influence on intestine, stomach, and spleen, as well as hepatoprotective activity (Błaszczyk et al. 2015; Suchecka et al. 2016). The extremely interesting from the bioactivity point of view is an antioxidant activity of oat fractions in vitro (Sang and Chu 2017) and especially the betaglucan in vivo (Suchecka et al. 2015) which action mechanism is still not clear and being associated both with residual phenolic content (Wang et al. 2017) and activity of multiple anomeric hydrogen atoms of carbohydrate polymers (Shah et al. 2017). The antioxidant activity of oat fractions, confirmed both in vitro and in vivo (Masisi et al. 2016), turns them into a valuable resource of antioxidants which can impact the total antioxidant activity of human plasma (Harasym and Oledzki 2014). Some study revealed that different processing of oat products can affect its bioactivity assessed as a content of antioxidants and beta-glucan (Ames et al. 2015); therefore, a thorough study is needed to evaluate the best possible treatment for each oat- 
containing product. Microwave radiation heating differs significantly from conventional cooking which is based on conduction and convection currents transporting heat from external sources. The capacity of water to absorb the energy from electromagnetic radiation results in friction caused by rotational movement of polarized or charged molecules trying to align to the alternating direction of electric field. The in situ heat generation not only alleviates the convectional transfer limitation but also creates superheated microsites facilitating the release of active components. Such environment was found as highly efficient in various food industry processes (Guo et al. 2017) and as medium supporting extraction (Ekezie et al. 2017). In cereals, processing the microwave treatment was used for inactivation of undesired enzymatic activity like betaglucanolytic (Pérez-Quirce et al. 2016) or lipolytic (Qian et al. 2009), to change the breadmaking properties of gluten-free flours (Pérez-Quirce et al. 2017), to assess the structural characteristic of beta-glucan (Ahmad et al. 2016), or to measure of antioxidant activity of cereal fraction (Dar and Sharma 2011; Stevenson et al. 2008).

Consumers' warm food using different heating methods however in case of preparing healthy food a microwave oven is undeservedly rejected being accused of nutritious property destruction. Contrary to preparing vegetables and fruits, the cereal grains need previous processing before being suitable for human consumption. The rising awareness of customers about the impact of healthy food eating leads to the renaissance of whole grain cereal food as whole grain flour, flakes, and bran. The last two products are of the most interest due to a high content of fibrous fraction and more botanical fractions of grain remaining intact which can simulate whole grain eating. Moreover, both of them can be eaten as breakfast or snack food; however, typical cooking is one of the limitations for the convenience of their usage. In Poland, eating oatmeal as breakfast cereals has been a long-lasting tradition, which contributes Poland being the top oat producer in the European Union with 1,458,623 t/year (FAOSTAT). The recent study of Polish consumer preference (Korzeniowska-Ginter and Kamińska 2014) has revealed that $41 \%$ of females and $56 \%$ of males perceive the important role of cereal products in nutrition, and almost $30 \%$ of females and $19 \%$ of males indicate that among all cereals, the oat has the most nutritious characteristic. Thirty-nine percent of all respondents confirmed that they consume oat products frequently with oat flakes as the first-choice position. Meanwhile, the oat bran, previously discarded and used as feed, now is gaining a lot of attention mainly as a rich source of dietary fiber particularly beta-glucan. In the following study, the comparison of two types of oat products was made in purpose to evaluate the release of bioactive substances into water extract obtained by microwave heating. The impact of morphological differences between products was also discussed. Therefore, we hypothesized that regarding the microwave usage is possible to obtain a more nutritious characteristic of oatmeal. The main objective of this study is to assess the impact of microwave radiation applied during food preparation on nutritionally important carbohydrates as starch, glucose, and beta-glucan extractability in water and their antioxidant activity. To our best knowledge, this is the first work comparing the impact of microwave irradiation on carbohydrate release and the antioxidant activity of water extracts from oat flakes and bran. The derivative objective of this study was to evaluate the secondorder relation between sample and treatment type as well as their mutual interactions with particular insight into the influence of sample morphology.

\section{Materials and Methods}

\section{Materials}

Oat flakes (Melvit, Poland) and bran (Sante, Poland) were purchased on the local market. The proximate content in $100 \mathrm{~g}$ (declared by manufacturer) of flakes and bran was carbohydrates -44.1 and $60.0 \mathrm{~g}$; fiber- 10.0 and $19.0 \mathrm{~g}$; fat -5.7 and $8.7 \mathrm{~g}$; and protein 13.0 and $17.6 \mathrm{~g}$, respectively. The estimated caloric load declared for both products was $363 \mathrm{kcal} / 100 \mathrm{~g}$. Distilled water was used for extraction. 2,2-Diphenyl-1picrylhydrazyl (DPPH), 2,2'-azino-bis (3-ethylbenzothiazoline6-sulphonic acid), Folin-Ciocalteu's reagent, gallic acid, sodium carbonate, and 6-hydroxy-2,5,7,8-tetramethylchroman-2-carboxylic acid were purchased from Sigma-Aldrich Ltd., Poland. $\beta$-Glucan Assay Kit (Mixed Linkage) and Total Starch Assay Kit (AA/AMG) of Megazyme International were purchased from Noack Polen Ltd., Poland.

\section{Morphology Evaluation}

The product samples were sieved with the vibratory sieve shaker Analysette 3 Spartan (Fritsch, Germany) at $0.5 \mathrm{~mm}$ vibration amplitude for 10 min with screens of $80,100,125$, $150,180,200,250,500,1000$, and $2000 \mu \mathrm{m}$. Due to the lower amount obtained in some fractions, they were merged in ranges $0-200,200-500,500-1000$, and 1000-2000 $\mu \mathrm{m}$. The images were taken with Digital Magnifier (DGCUS, China) before and after each sample treatment. The remaining solid particles were taken from the treatment vessel and left for drainage on filter paper, and the images were taken with Digital Magnifier at two magnifications $\times 250$ and $\times 500$.

\section{Water Uptake Indices}

The water uptake indices were assessed by water holding capacity (WHC) and water solubility index (WSI) (basing on AACC 88-04 with some modifications for oat flakes and bran). Briefly, $5 \mathrm{~g}$ of sample was added into pre-weighed 
$50-\mathrm{mL}$ centrifuge tube filled with $30 \mathrm{~mL}$ of distilled water. The sample was left until sediment and then left for $24 \mathrm{~h}$. Then, the sample was centrifuged for $15 \mathrm{~min}$ at $3000 \mathrm{~g}$ (MPW352R, MPW, Poland). The solids residue was weighted and water capacity was expressed as percent per gram of sample dry basis (d.b.). The supernatant was carefully discarded into pre-weighed capsules, weighed, and put into an oven at $110{ }^{\circ} \mathrm{C}$ for $24 \mathrm{~h}$. The solid content in the supernatant was calculated and expressed as WSI of percent per gram of sample d.b.

\section{Sample Processing}

Fifty grams of oat product was placed in glass round-bottom flask and mixed with distilled water in a ratio of 1:10 (w/w) solid:liquid. The flask was placed inside the microwave reactor (NOVA 10, Ertec, Poland) of $750 \mathrm{~W}$ maximum power and $2.45 \mathrm{GHz}$ frequency, with reflux glass column cooled with running tap water, infrared thermometer, and magnetic stirrer. The magnetic stirring bar was located inside the flask. The stirrer was turned on for $10 \mathrm{~s}$ of each minute of treatment. The microwave irradiation was performed for $1,2,3$, and $5 \mathrm{~min}$. After each treatment, the sample was divided into four centrifuge tubes and centrifuged for $10 \mathrm{~min}$ at $5000 \times \mathrm{g}$ (MPW352R, MPW, Poland); the supernatant was gathered and used for analysis the same day. The control of typical cooking was done in a glass pot with glass cover heated on a magnetic stirrer heating plate (BIOSAN, Poland) until boiling with similar stirring intervals.

\section{Chemical Content Analysis}

Proximate chemical composition measurement was done following methods in accordance with the AOAC (1996) for moisture, total ash, fat, and protein while carbohydrates were calculated by resting. The insoluble (IDF) and soluble (SDF) dietary fiber contents of the samples were determined with an enzymatic-gravimetric method, based on the AOAC 991.42, AOAC 993.19, and AACC 32-21 (AOAC, 1990), and total dietary fiber (TDF) content was calculated as a sum of SDF and IDF. The beta-glucan content in oat flakes and bran without processing as well as in supernatant was measured according to a procedure described in $\beta$-Glucan (Mixed Linkage) Assay Kit (Megazyme International Ireland, Ltd. Ireland). The starch content was measured in raw oat products and supernatant with Total Starch Assay Kit (Megazyme International Ireland, Ltd. Wicklow, Ireland). The moisture content of samples was determined gravimetrically (Sartorius Moisture Analyzer MA30, Sartorius AG, Germany). The available glucose was measured with GOPOD reagent (Megazyme International Ireland, Ltd. Ireland). All the measurement was taken in triplicate, and results were reported as $\mathrm{g} / 100 \mathrm{~g}$ of sample d.b. in oat flakes and bran.

\section{Antioxidant Analysis}

\section{Total Phenolic Content}

The Folin-Ciocalteu spectrophotometric method was used for the total phenolic content determination and expressed as gallic acid equivalents per gram of sample (Prior et al. 2005).

\section{DPPH Method}

Antioxidant activity was measured with 2,2-diphenyl-1picrylhydrazyl and 2,2'-azino-bis(3-ethylbenzothiazoline-6sulphonic acid) method (Prior et al. 2005), and results were expressed as Trolox equivalent per gram of sample.

\section{ABTS TEAC Method}

Antioxidant activity was measured with 2,2-diphenyl-1picrylhydrazyl and 2,2'-azino-bis(3-ethylbenzothiazoline-6sulphonic acid) method (Prior et al. 2005), and results were expressed as Trolox equivalent per gram of sample.

\section{Statistical Analysis}

The results were taken in triplicate and reported as means with standard deviation. The analysis of variance (ANOVA) for mean values of extract components between different treatments and raw materials was assessed with $p<0.05$ significance level. The multivariate analysis (MANOVA) was carried to assess second-order relation between sample and treatment. The Pearson correlation and partial correlation coefficients were calculated between extract components and antioxidant activity with Statgraphics Centurion XVII (Bitstream, Cambridge, USA) at a probability level of $p<0.05$.

\section{Results and Discussion}

\section{The Comparison of Nutritional Component Content}

The nutritional facts delivered by manufactures mainly focused on carbohydrate difference (Fig. 1) while nutritional component characteristic (Table 1) revealed that oat bran surpasses the oat flakes of $20 \%$ in protein, total dietary fiber, and ash content. The specific analysis of fiber fractions showed that only significant difference was for soluble dietary fiber (higher of $70 \%$ and mainly beta-glucan). In oat flakes, the starch and free glucose contents were higher about 13 and $16 \%$ respectively. 


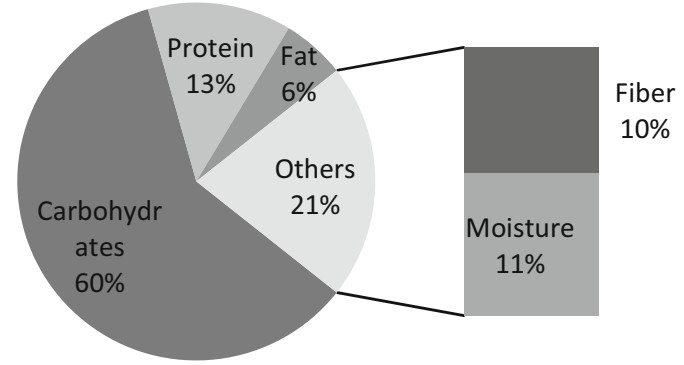

a)

Oat flakes - calorific value $363 \mathrm{kcal} / 100 \mathrm{~g}$

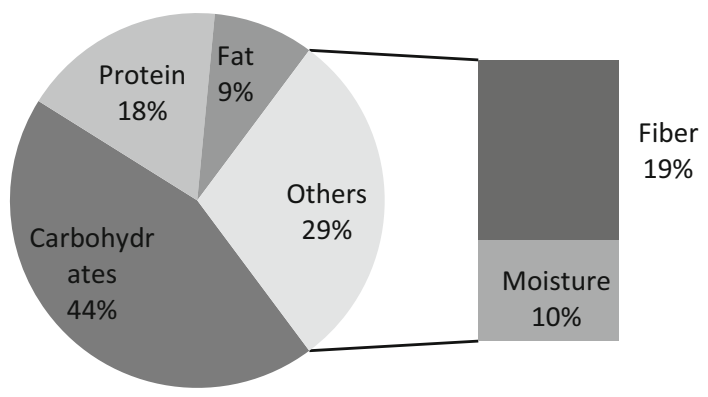

b)

Oat bran- calorific value $363 \mathrm{kcal} / 100 \mathrm{~g}$

Fig. 1 a, b The manufacturers' declared nutrition composition of oat raw materials

The nutritional composition of oat bran was similar to the fraction of medium bran as reported by Hitayezu et al. (2015), but the carbohydrate content was lower. The same was for oat flakes where protein and fat values were similar while carbohydrate content was much higher. As nutritional component content depends on variety, cultivation conditions, and processing, the comparison with data of products made from Poland cultivated oat was made and revealed that for oat flakes, most of the components were comparable with previously reported e.g., moisture $(10.44 ; 7.96 ; 9.21)$, ash (1.71; $1.73 ; 1.6)$, protein $(13.56 ; 15.2 ; 12.5)$, fat $(9.08 ; 8.85 ; 6.71)$, and $\operatorname{TDF}(17,18,20)$ (Rzedzicki and Wirkijowska 2008), and the same was for bran (Rzedzicki 2006). The values of calorific load declared by the manufacturer were incomparable with research results which have clearly indicated the superiority of oat bran due to lower calorific overall load, higher content of protein, total dietary fiber, beta-glucan, and ash content.

Table 1 The nutritional composition of oat raw materials in \% per dry basis (mean $\pm \mathrm{SD}$ ) except calorific value (kcal/100 $\mathrm{g}$ of dry basis)

\begin{tabular}{lll}
\hline & OF & OB \\
\hline Protein & $13.88 \pm 0.71 \mathrm{a}$ & $16.77 \pm 2.32 \mathrm{~b}$ \\
Fat & $9.00 \pm 0.98 \mathrm{a}$ & $7.14 \pm 1.57 \mathrm{a}$ \\
Carbohydrate & $48.48 \pm 1.74 \mathrm{~b}$ & $42.67 \pm 1.13 \mathrm{a}$ \\
Starch & $47.03 \pm 1.69 \mathrm{~b}$ & $41.39 \pm 1.09 \mathrm{a}$ \\
Glucose & $1.00 \pm 0.04$ & $0.6 \pm 0.02$ \\
TDF & $17.6 \pm 1.21 \mathrm{a}$ & $21.3 \pm 1.2 \mathrm{~b}$ \\
SDF & $6.0 \pm 0.8 \mathrm{a}$ & $10.42 \pm 0.61 \mathrm{~b}$ \\
Beta-glucan & $4.73 \pm 0.38 \mathrm{a}$ & $6.1 \pm 0.48 \mathrm{~b}$ \\
IDF & $11.66 \pm 2.08 \mathrm{a}$ & $12.73 \pm 2.96 \mathrm{a}$ \\
Ash & $1.64 \pm 0.08 \mathrm{a}$ & $2.08 \pm 0.21 \mathrm{~b}$ \\
Moisture & $9.39 \pm 1.84 \mathrm{a}$ & $10.04 \pm 0.89 \mathrm{a}$ \\
Calorific value & $312.48 \pm 7.94 \mathrm{~b}$ & $287.75 \pm 3.17 \mathrm{a}$ \\
\hline
\end{tabular}

Mean values with different small letters imply significant differences between means in row at $p<0.05$

$O F$ oat flakes, $O B$ oat bran, $T D F$ total dietary fiber, $I D F$ insoluble dietary fiber, $S D F$ soluble dietary fiber

\section{Morphology of Raw Materials}

The oat product size distribution revealed that more than $50 \%$ of bran particles were bigger than $500 \mu \mathrm{m}$ and the flakes were almost twice bigger in $75 \%$ (Table 2). The $25 \%$ of flakes was uniformly divided into two fractions - a bigger one- like oat bran - and the fraction smaller than $200 \mu \mathrm{m}$. The bran has the fraction of $33 \%$ between 200 and $500 \mu \mathrm{m}$ and $16 \%$ below $200 \mu \mathrm{m}$.

As oat flakes are produced by flattening the whole or steelcut groats with rotating rollers (Girardet and Webster 2011), the regulated roller gaps result in a different thickness of flakes. The ones used in the research study were morphologically comparable to whole-oat flakes $(0.51-0.76 \mathrm{~mm})$ (Decker et al. 2014) which were confirmed by microphotography (Fig. 2). After rolling, to remove clumps of flakes, fines, and small flakes, they are passed through the sieves and then packed which means that fine powder presence results from crushing of the ready product in the package. The used sample was almost uniform with about $10 \%$ of ruptured particles. The higher rupture and lower moisture content may indicate that the product was badly packed, stored, or handled.

The oat bran can be obtained in two different processesas residues from flour manufacturing or by milling the previously prepared flakes. Because further they are sieved, there are no possibilities to distinct them by morphology, but because flakes production needs hydrothermal treatment which pregelatinizes the starch, the difference can be seen in the functional properties of oat bran. The water uptake indices (Table 2) revealed similar water holding capacity for the samples while $25 \%$ different solubilization index was noted and related (as further confirmed) to an abundance of easily soluble components. A steam treatment, necessary for softening the grain before rolling, pregelatinizes the starch and facilitates its further dissolution in the water leading to the appearance of water-soluble dextrin and simple sugars. As WSI (water solubility index) is not correlated with small particle size fraction being higher for oat flakes than for oat bran, it may suggest that oat bran was not obtained from oat flakes. The 
Table 2 The particle size distribution of oat products [\%] and water uptake indices $[\% / g$ d.b.]

\begin{tabular}{lllllll}
\hline & $0-200 \mu \mathrm{m}$ & $200-500 \mu \mathrm{m}$ & $500-1000 \mu \mathrm{m}$ & $1000-2000 \mu \mathrm{m}$ & WHC & WSI \\
\hline OF & $10.5 \pm 0.71 \mathrm{a}$ & $3.5 \pm 0.91 \mathrm{a}$ & $12.32 \pm 2.14 \mathrm{a}$ & $74.3 \pm 5.26 \mathrm{~b}$ & $127.44 \pm 0.05 \mathrm{a}$ & $4.05 \pm 0.05 \mathrm{~b}$ \\
OB & $16.1 \pm 0.32 \mathrm{~b}$ & $33.1 \pm 1.21 \mathrm{~b}$ & $51.27 \pm 3.28 \mathrm{~b}$ & $0 \mathrm{a}$ & $122.8 \pm 1.26 \mathrm{a}$ & $3.7 \pm 0.07 \mathrm{a}$ \\
\hline
\end{tabular}

Mean values with different small letters imply significant differences between means in column at $p<0.05$

$O F$ oat flakes, $O B$ oat bran, $W H C$ water holding capacity, WSI water solubility index morphology of oat product particle visible on Fig. 2 reveals that oat flakes are uniform and repeat more or less the original grain form with big parts of outer layer intact and several scratches and breakings showing endosperm. The outer layer parts in oat bran fraction are big, and endosperm part is thin and not glued to aleurone layer suggesting that oat bran was obtained from flour milling. Several studies have reported that moisture, temperature, and time are the most significant parameters that affect the mechanical properties of cereals confirming the internal structure difference between thick and thin oat flakes (Gates et al. 2008). Changes occurring in effect of faster relaxation of higher moisture content samples during the softening process origin from the secondary structure of proteins modification, starch granules gelatinization, and water holding capacity of fibrous material (Ozturk and Takhar 2017) which is transferred to the type of nutritional component released during further processing.

\section{The Morphological Change and Carbohydrate Release During Microwave Irradiation}

The changes of sample morphology (Table 3) and the solids release, as well as their content of starch, glucose, and betaglucan (Table 4), were evaluated in relation to treatment and sample type as well as temperature and time. Depending on a heating method and time, the solids release to water phase almost in all samples. The solids content subsequently raised with processing time, except MW1 in oat flakes, which was probably caused by low processing temperature and resulting intact morphology of oat flakes (Table 3).

The similar behavior was observed by Yiu et al. (1991) for 1 min microwaved and conventionally cooked oat flake porridge, where they obtained the very similar content of supernatants, while the highest values obtained come from $20 \mathrm{~min}$ of conventional cooking. The proportional content of starch in solids was decreasing with temperature and time increase of the treatment while being the lowest in conventionally cooked oat flakes and bran. However, it was almost $23 \%$ higher in the bran meal, which can be caused by the previous pregelatinization of starch in flakes (Tables 3 and 4) and its further depolymerization during the heating.

The MW irradiation resulted in minimal glucose release from flakes during first $2 \mathrm{~min}$ of treatment, while in case of oat bran meal, the content increased significantly in $2 \mathrm{~min}$ of MW treatment. The morphology imaging reveals that the surface of flake did not change, while in oat bran was noted a gloss. The effect probably resulted from efficient hydration of remaining endosperm which can be further related to the higher release of non-bound internal components. The betaglucan proportional content increased only with the temperature rise of processing and was comparable for all treatments overcrossing the gelatinization temperature (e.g., MW3, MW5, and CH7 (see Table 3)). The second-order correlations between sample and treatment impact revealed that for all samples, the treatment was the most significant factor changing the chemical characteristic of oatmeal liquid phase. The double interaction was also statistically significant for starch, glucose, and total solids content except for the beta-glucan, which was independent of the mutual interaction. Comparing only the impact of treatment type on different samples, it was noted the mutual interaction of second order between the glucose and starch content; however, the interaction was strong with $p<0.001$ for starch while for glucose only $p<0.05$. In that case, the carbohydrate characteristic in liquid phase
Fig. 2 Morphology of oat flakes (OF) and bran (OB)
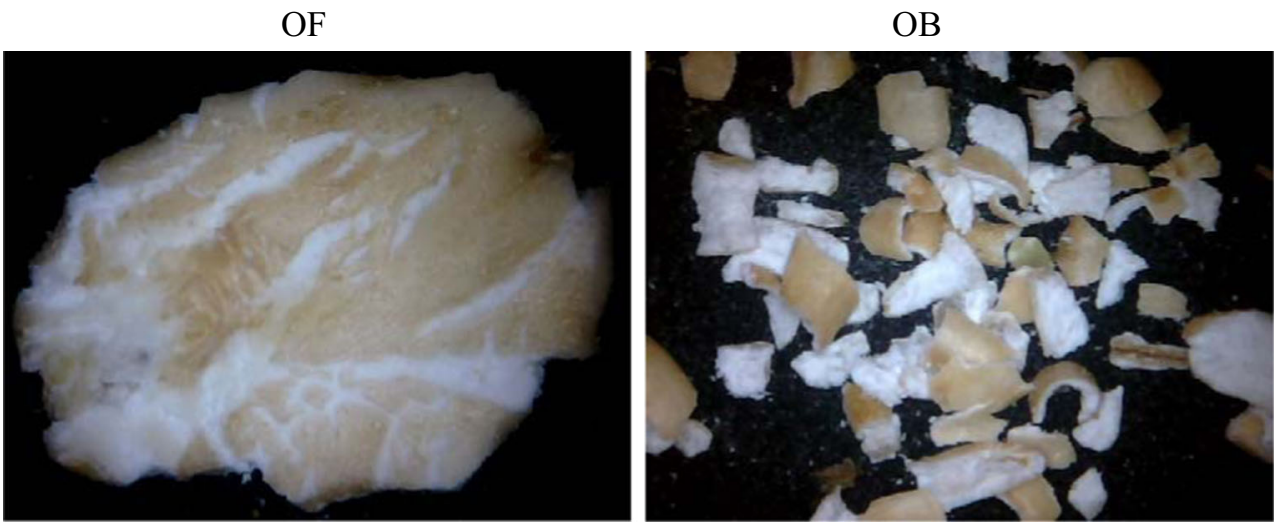
Table 3 Morphological changes of oat raw materials particles after microwave irradiation

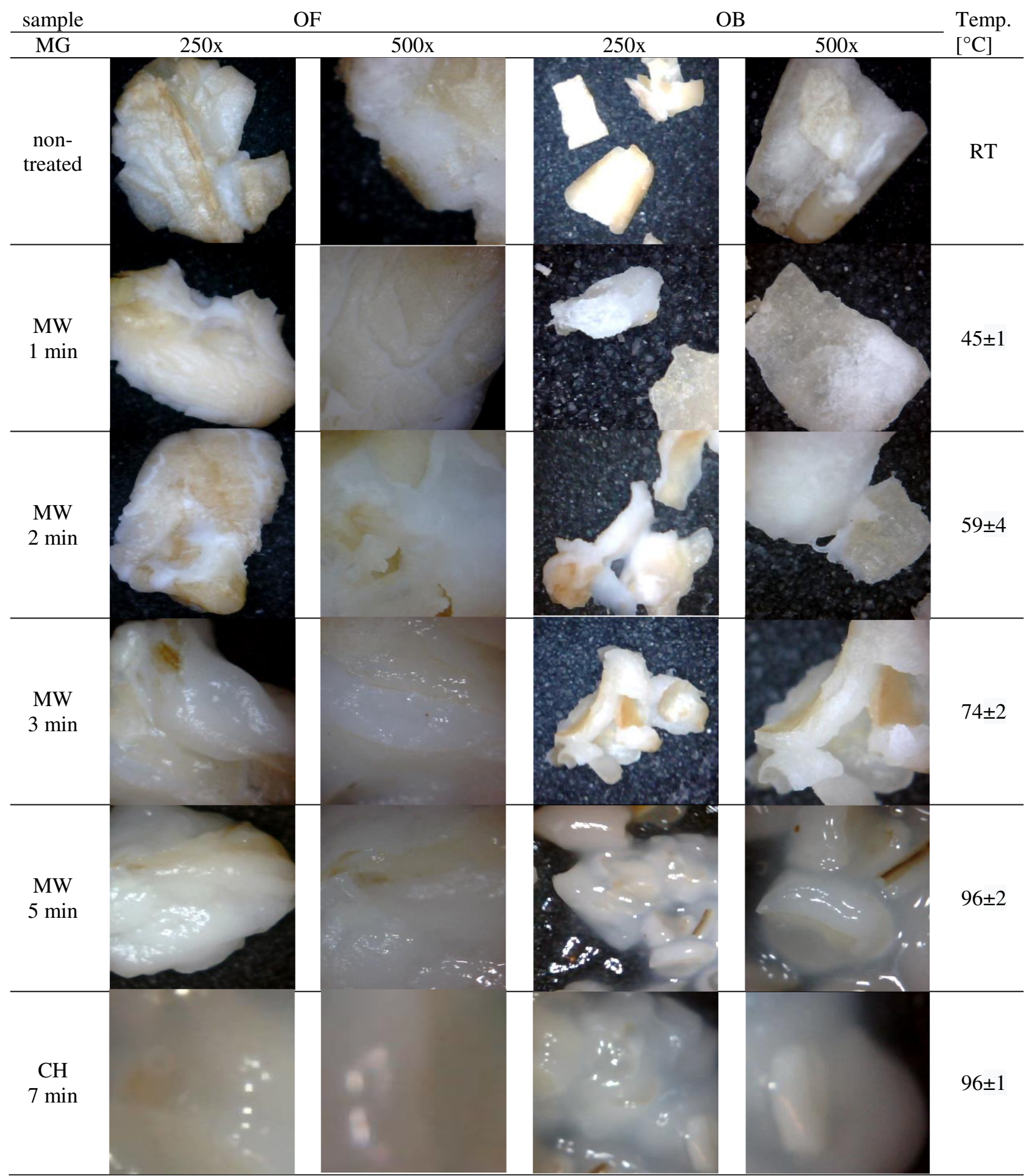

$O F$ oat flakes, $O B$ oat bran, $M G$ magnification, $R T$ room temperature, $C H$ convectional heating, $M W$ microwave heating

depends on achieving the gelatinization temperature, but the special restrictions coming from more or less intact original matrix can also influence the obtained results. The further statistical calculation of a difference between all three processing conditions vs. the gelatinization temperature revealed that the solids release was the highest for typical cooking while the content of non-hydrolyzed starch was the highest in MW irradiated samples especially in shorter treatment (MW3). The oat flakes have initial higher starch content due both the morphological form and processing method (Decker et al. 2014). The overall starch content of oat bran is also high because of residual fat and protein presence in aleuronic layer in oat grain which makes full separation of endosperm impossible. The available glucose content was higher in oat flakes 


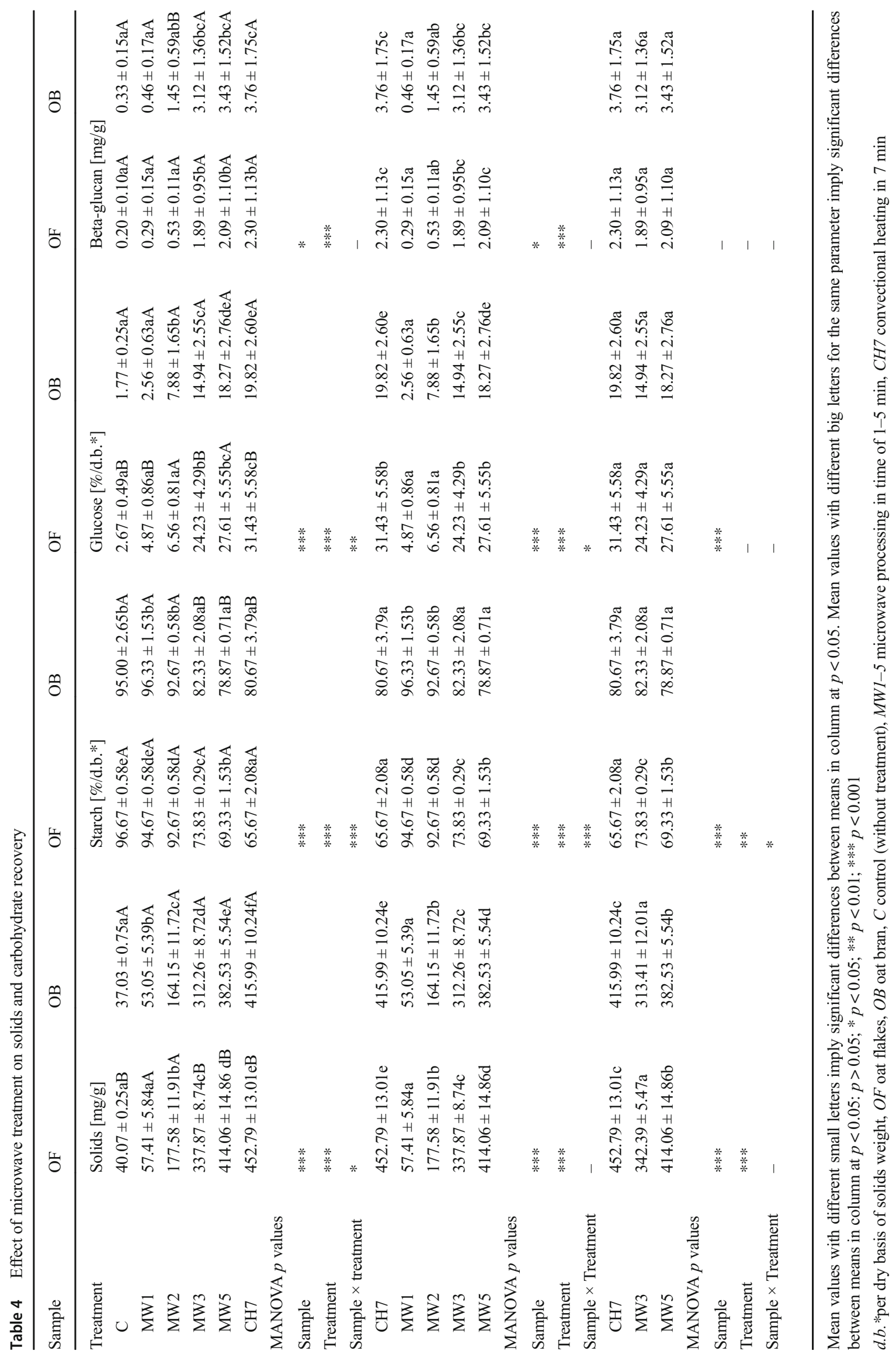


which can be the result of pregelatinization taking place during steaming for flaking. The results are consistent with the observation of Itagi et al. (2012) who reported higher swelling power for barley and wheat flakes as well as the highest solubility of wheat flakes. Also, Stevenson et al. (2008) reported that soluble solids were lowest in the coarsest fraction of oat bran. It was supposed that starch content could be much higher in bran than that in flakes because bran used in this study had the higher content of smallest fraction. But it seems that the smallest bran fraction consists rather of outer layer crushed particles as betaglucan content was much higher than that in flakes.

The convectional heating released the highest amount of solids from both sample types, while 4 min of flake microwave irradiation resulted in similar to conventional heating, amounts of solids released of bran. The conventional heating also had the strongest impact on starch decomposition in flakes and $63 \%$ higher glucose release which was probably connected with higher susceptible to depolymerization of pregelatinized starch. In bran, there was no such relation observed and the highest decomposition was provided with MW5 heating. However, there was no difference between glucose content observed from $\mathrm{CH} 7$ and MW5. The betaglucan release started where heating temperature achieved the temperature of starch gelatinization and was noted being $50 \%$ higher for bran. The beta-glucan content was the highest in both 5-min microwave and conventionally cooked oat bran, while in oat flakes, the beta-glucan values were significantly lower in the supernatant, which was probably caused by morphological hindrance of native flake structure. Yiu et al. (1991) also observed for thin and thick oat flakes that integrity of structural components during heating had a significant impact on starch and beta-glucan release confirming the easier release of compounds from thin and cut items.

\section{Antioxidant Activity of Water Extract}

The antioxidant activities assessed in function of sample type, treatment, and temperature impact as TPC, DPPH, and ABTS values revealed important differences (Table 5).

The activity of phenol-like acting components expressed as gallic acid equivalent was the highest in oat bran sample irradiated with microwaves for 5 min and was even 17\% higher than those obtained from the milled sample used as a control. The antioxidant activity vs. DPPH radicals revealed the highest values for both long-time MW heating procedures being also higher than control samples. About $40 \%$ higher

Table 5 Effect of microwave treatment on antioxidant activity of water extracts

\begin{tabular}{|c|c|c|c|c|c|c|}
\hline Sample & $\mathrm{OF}$ & OB & $\mathrm{OF}$ & OB. & $\mathrm{OF}$ & OB. \\
\hline Treatment & TPC & & DPPH & & ABTS & \\
\hline $\mathrm{C}$ & $9.47 \pm 0.20 \mathrm{eB}$ & $8.86 \pm 0.26 \mathrm{cA}$ & $3.06 \pm 0.05 \mathrm{bA}$ & $2.94 \pm 0.10 \mathrm{aA}$ & $6.47 \pm 0.21 \mathrm{bA}$ & $7.27 \pm 0.25 \mathrm{cB}$ \\
\hline MW1 & $3.63 \pm 0.06 \mathrm{aA}$ & $4.43 \pm 0.25 \mathrm{aB}$ & $2.24 \pm 0.15 \mathrm{aA}$ & $3.07 \pm 0.21 \mathrm{aB}$ & $4.23 \pm 0.26 \mathrm{aA}$ & $5.28 \pm 0.32 \mathrm{aB}$ \\
\hline MW2 & $6.03 \pm 0.16 \mathrm{bA}$ & $6.76 \pm 0.29 \mathrm{bB}$ & $3.25 \pm 0.15 \mathrm{aA}$ & $4.31 \pm 0.09 \mathrm{bB}$ & $6.03 \pm 0.33 \mathrm{bA}$ & $6.48 \pm 0.14 \mathrm{bA}$ \\
\hline MW3 & $8.30 \pm 0.20 \mathrm{cA}$ & $10.00 \pm 0.11 \mathrm{~dB}$ & $4.65 \pm 0.21 \mathrm{dA}$ & $6.25 \pm 0.26 \mathrm{~dB}$ & $8.17 \pm 0.38 \mathrm{cA}$ & $8.70 \pm 0.23 \mathrm{dA}$ \\
\hline MW5 & $8.96 \pm 0.08 \mathrm{dA}$ & $10.42 \pm 0.11 \mathrm{eB}$ & $4.83 \pm 0.06 \mathrm{dA}$ & $6.60 \pm 0.38 \mathrm{~dB}$ & $8.71 \pm 0.24 \mathrm{cA}$ & $9.25 \pm 0.20 \mathrm{eB}$ \\
\hline $\mathrm{CH} 7$ & $8.15 \pm 0.05 \mathrm{cA}$ & $9.15 \pm 0.04 \mathrm{cB}$ & $4.15 \pm 0.05 \mathrm{cA}$ & $5.53 \pm 0.16 \mathrm{cB}$ & $8.37 \pm 0.50 \mathrm{cA}$ & $8.34 \pm 0.23 \mathrm{~dB}$ \\
\hline \multicolumn{7}{|l|}{ MANOVA $p$ values } \\
\hline Sample & $* * *$ & & $* * *$ & & $* * *$ & \\
\hline Treatment & $* * *$ & & $* * *$ & & $* * *$ & \\
\hline Sample $\times$ Treatment & $* * *$ & & $* * *$ & & - & \\
\hline MW1 & $3.63 \pm 0.06 \mathrm{a}$ & $4.43 \pm 0.25 \mathrm{a}$ & $2.24 \pm 0.15 \mathrm{a}$ & $3.07 \pm 0.21 \mathrm{a}$ & $4.23 \pm 0.26 \mathrm{a}$ & $5.28 \pm 0.32 \mathrm{a}$ \\
\hline MW2 & $6.03 \pm 0.16 b$ & $6.76 \pm 0.29 b$ & $3.25 \pm 0.15 b$ & $4.31 \pm 0.09 b$ & $6.03 \pm 0.33 b$ & $6.48 \pm 0.14 b$ \\
\hline MW3 & $8.30 \pm 0.20 c$ & $10.00 \pm 0.11 \mathrm{~d}$ & $4.65 \pm 0.21 d$ & $6.25 \pm 0.26 \mathrm{~d}$ & $8.17 \pm 0.38 \mathrm{c}$ & $8.70 \pm 0.23 c$ \\
\hline MW5 & $8.96 \pm 0.08 \mathrm{~d}$ & $10.42 \pm 0.11 \mathrm{e}$ & $4.83 \pm 0.06 \mathrm{~d}$ & $6.60 \pm 0.38 \mathrm{~d}$ & $8.71 \pm 0.24 \mathrm{c}$ & $9.25 \pm 0.20 \mathrm{~d}$ \\
\hline $\mathrm{CH} 7$ & $8.15 \pm 0.05 c$ & $9.15 \pm 0.04 \mathrm{c}$ & $4.15 \pm 0.05 \mathrm{c}$ & $5.53 \pm 0.16 \mathrm{c}$ & $8.37 \pm 0.50 \mathrm{c}$ & $8.34 \pm 0.23 \mathrm{c}$ \\
\hline \multicolumn{7}{|l|}{ MANOVA $p$ values } \\
\hline Sample & $* * *$ & & $* * *$ & & $* * *$ & \\
\hline Treatment & $* * *$ & & $* * *$ & & $* * *$ & \\
\hline Sample $\times$ Treatment & $* * *$ & & $* *$ & & - & \\
\hline
\end{tabular}

Mean values with different small letters imply significant differences between means in column at $p<0.05$. Mean values with different big letters for the same parameter imply significant differences between means in columns at $p<0.05$. No statistically significant: $p>0.05 ; * p<0.05$; ** $p<0.01$; *** $p<0.001$

$O F$ oat flakes, $O B$ oat bran, $C$ control (without treatment), $M W 1-5$ microwave processing in time 1-5 min, $C H 7$ convectional heating in 7 min

*Per the dry basis of solids weight 
activity was observed for both long times of MW radiation in bran meal comparing to flakes. The ABTS scavenging activity was the highest in MW5 treated samples of bran meal while in flakes there was no significant difference between all treatments crossing the gelatinization temperature. Second-order interaction of factors revealed that all antioxidant activity values were dependent on both sample and treatment while mutual interaction was statistically significant only for TPC and DPPH (Table 5).

The water extracts of bran and flakes obtained in room temperature by $1 \mathrm{~h}$ of intensive stirring of well-milled sample exceeded the literature data and were significantly different with 8.9 and $9.4 \mathrm{mg}$ of gallic acid equivalent per gram of d.b. respectively. However, the vast majority of studies is mainly focused on organic solvent extraction evaluation and aims at the assessment of particular phenolic acid presence and their content in oat products. The antioxidant activity depends on many factors (e.g., the variety, cultivation conditions, grain fraction, extraction procedure, and solvents), so it is almost impossible to make a direct comparison with literature data.

Much research was done for finding the proper solvent combination. Pérez-Jiménez and Saura-Calixto (2005) testing various aqueous ethanol, methanol, or acetone mixtures found that far more phenolics (expressed as TPC in sum of extractable and hydrolysable phenolic compounds and its gallic acid equivalents) can be extracted from oat bran if the two subsequent extractions were applied- $1.95 \mathrm{mg} / \mathrm{g}$ for extractable phenolic compounds and $9.71 \mathrm{mg} / \mathrm{g}$ for hydrolysable ones obtained from solid residues after the first extraction. However, using milder conditions without organic solvent but with help of simulation of human digestion process resulted in TPC values of $8.45 \mathrm{mg} / \mathrm{g}$ in oat bran while $4.34 \mathrm{mg} / \mathrm{g}$ of phenolics was assessed in solid residues (Alrahmany et al. 2013).

Very few works have been done on water extracts of oat products to assess TPC and antioxidant activity. Zieliński and Kozłowska (2000) found that for whole oats, the $80 \%$ methanol extract had substantially higher total phenolic compounds (17.6 vs. $1.5 \mu \mathrm{g}$ catechin/mg lyophilizate, respectively) and exhibited higher antioxidant capacity ( 0.08 vs. $0.03 \mu \mathrm{mol}$ Trolox/lyophilizate, respectively) than water extracts; however, the number of components extracted by water generally was higher as compared to that extracted by $80 \%$ methanol. Stevenson et al. (2008) assessed the effectiveness of water, ethanol, and their equal mixture, to extract phenolics and other antioxidant compounds from the ground oat bran concentrate (OBC). The obtained TPC was $9.2 \mathrm{mg} / \mathrm{g}$ of defatted oat bran which means that it was ten times higher than obtained by Hitayezu et al. (2015) and Chu et al. (2013) for both methanolic and acetone solvents-presumed as the best, while antioxidant capacity (DPPH, expressed as Trolox $\mu \mathrm{mol} / \mathrm{g}$ equivalent) was the highest for $50-50 \mathrm{w} / \mathrm{w}$ extracts and the statistically significant closest ones were water extracts from defatted and non-defatted OBC.

\section{Correlation Between Solids Component Recovery and Antioxidant Activity of Water Extracts}

The partial coefficients of multivariate correlation analysis (Table 6) revealed the strong negative correlation between glucose and starch $(-0.82)$ in flake meal while in bran meal, there was a strong positive correlation between glucose and solids $(0.98)$. The partial correlation coefficient measures the

Table 6 Correlation coefficients between water extract components

\begin{tabular}{|c|c|c|c|c|c|c|c|c|}
\hline & & Solids & Starch & Glucose & Beta-glucan & TPC & DPPH & ABTS \\
\hline \multirow[t]{2}{*}{ Solids } & $\mathrm{OF}$ & & $-0.97 * * *$ & $0.94 * * *$ & $0.78 * * *$ & $0.95^{* * *}$ & $0.90^{* * *}$ & $0.95^{* * *}$ \\
\hline & $\mathrm{OB}$ & & $-0.95 * * *$ & $0.96 * * *$ & $0.78 * * *$ & $0.93 * * *$ & $0.89 * * *$ & $0.93 * * *$ \\
\hline \multirow[t]{2}{*}{ Starch } & $\mathrm{OF}$ & $-0.65 *$ & & $-0.97 * * *$ & $-0.80 * * *$ & $-0.90 * * *$ & $-0.87 * * *$ & $-0.92 * * *$ \\
\hline & $\mathrm{OB}$ & - & & $-0.90 * * *$ & $-0.80 * * *$ & $-0.94 * * *$ & $-0.92 * * *$ & $-0.96^{* * *}$ \\
\hline \multirow[t]{2}{*}{ Glucose } & $\mathrm{OF}$ & - & $-0.82 * *$ & & $0.90^{* * *}$ & $0.87 * * *$ & $0.83^{* * *}$ & $0.89^{* * *}$ \\
\hline & $\mathrm{OB}$ & $0.98 * * *$ & - & & $0.59 *$ & $0.89 * * *$ & $0.88 * * *$ & $0.89 * * *$ \\
\hline \multirow[t]{2}{*}{ Beta-glucan } & $\mathrm{OF}$ & - & - & $0.89 * * *$ & & $0.73 * *$ & $0.70 * *$ & $0.73 * *$ \\
\hline & OB & $0.98 * * *$ & - & $-0.97 * * *$ & & $0.75^{* *}$ & $0.67 * *$ & $0.78 * * *$ \\
\hline \multirow[t]{2}{*}{ TPC } & $\mathrm{OF}$ & $0.71 *$ & - & - & - & & $0.98 * * *$ & $0.99 * * *$ \\
\hline & $\mathrm{OB}$ & - & - & - & - & & $0.98 * * *$ & $0.99 * * *$ \\
\hline \multirow[t]{2}{*}{ DPPH } & $\mathrm{OF}$ & $-0.66^{*}$ & - & - & - & $0.87 * *$ & & $0.96^{* * *}$ \\
\hline & $\mathrm{OB}$ & - & - & - & - & $0.71 *$ & & $0.96 * * *$ \\
\hline \multirow[t]{2}{*}{ ABTS } & $\mathrm{OF}$ & - & - & - & - & $0.74 *$ & - & \\
\hline & $\mathrm{OB}$ & - & - & - & - & - & - & \\
\hline
\end{tabular}

Values in italics represent partial coefficients $-p>0.05 ; * p<0.05 ; * * p<0.01 ; * * * p<0.001$

$O F$ oat flakes, $O B$ oat bran 
strength of the linear relationship between the variables having first adjusted for their relationship to other variables. In this case, it can be concluded that glucose content in oat flake meal comes from hydrolyzed pregelatinized starch, while in oat bran it is more connected with milling process as glucose content has a high positive correlation with starch content.

The sample type impact was also very well correlated with treatment except for beta-glucan, where the statistical significance was $p>0.05$. The partial coefficient for beta-glucan revealed its strong correlation with the presence of glucose in the water phase of flakes and bran meal, positive and negative, respectively. The second-order correlation between thermal treatment impact and a sample was also assessed as ANOVA results revealed no statistically significant differences in carbohydrate proportional content, while it is known that thermal treatment changes the molecular characteristic of carbohydrate polymers. The analysis showed the further relations of thermal treatment in function of reaching or not the starch gelatinization temperature. All thermal treatments significantly impacted mainly on starch, while in case of maximum time of microwave heating, the results were insignificantly different from the convectional heated meal, which was the opposite effect when comparing to sample type influence. The solids release depended only on treatment or sample with lack of any mutual interaction. Meanwhile, the shorter time ( $3 \mathrm{~min}$ ) of microwave heating seems to be more balanced treatment when looking for the sample type effect difference because second-order correlation shows strong dependence from sample type used. The typical heating conditions based on convectional heat transfer needed more time to obtain boiling state which finally leads to the highest solids content from both products type (Table 4).

The antioxidant activity of water extracts is strongly correlated with solids content and carbohydrate characteristic of oat meal liquid phase. Also, the specific sample morphology should be taken into account as ANOVA of samples revealed different release. For each type of assay, there were statistically significant differences between samples especially in TPC and the partial coefficient correlations revealed strong positive dependence between TPC and ABTS values. MANOVA showed that second-order relation was statistically significant in ABTS only for treatment and sample, while their mutual interaction was not observed. The thermal treatment (MW1-5, $\mathrm{CH7}$ ) raised TPC and DPPH values depending on both factors and their mutual interaction, while ABTS was still dependent only on each one of them. Similarly, as in case of carbohydrate content, the shorter time of microwave heating provided a similar to MW5 results except for no correlation with ABTS values. The Pearson coefficient analysis showed that regardless the sample used in each treatment, the DPPH and ABTS values were strongly positively correlated with solids, glucose, and beta-glucan content and negatively correlated with starch presence. Meanwhile, the TPC values from flake meal comparing to bran meal were statistically insignificant revealing the huge impact of sample morphology because TPC value of oat bran has, similar to DPPH and ABTS, a good correlation (approx. 0.60-0.70) with carbohydrate characteristic.

\section{Conclusions}

Microwave irradiation used for heating has a positive impact on native cereal matrix modification leading to release of nutritional compounds into water extracts. Oat bran with lower calorific load can be used as nutritious whole grain breakfast cereal as they deliver high amounts of slowly digested carbohydrates and solids with antioxidant activity. Especially for minimally processed cereal food, the microwave heating can deliver much more beneficial compounds than conventional cooking, which due to the prolonged time of heat treatment delivers finally a higher amount of too many easily digested carbohydrates which may cause a high glycemic response.

Funding Information This study was supported by National Science Centre (Narodowe Centrum Nauki), Poland, through the grant no. NN312506640.

Open Access This article is distributed under the terms of the Creative Commons Attribution 4.0 International License (http:// creativecommons.org/licenses/by/4.0/), which permits unrestricted use, distribution, and reproduction in any medium, provided you give appropriate credit to the original author(s) and the source, provide a link to the Creative Commons license, and indicate if changes were made.

\section{References}

Ahmad, M., Gani, A., Shah, A., Gani, A., \& Masoodi, F. A. (2016). Germination and microwave processing of barley (Hordeum vulgare $L$ ) changes the structural and physicochemical properties of $\beta-\mathrm{d}-$ glucan enhances its antioxidant potential. Carbohydrate Polymers, 153, 696-702. https://doi.org/10.1016/j.carbpol.2016.07.022

Alrahmany, R., Avis, T. J., \& Tsopmo, A. (2013). Treatment of oat bran with carbohydrases increases soluble phenolic acid content and influences antioxidant and antimicrobial activities. Food Research International, 52(2), 568-574. https://doi.org/10.1016/j.foodres. 2013.03.037

Ames, N., Storsley, J., \& Tosh, S. (2015). Effects of processing on physicochemical properties and efficacy of $\beta$-glucan from oat and barley. Cereal Foods World, 60(1), 4-8. https://doi.org/10.1094/CFW-60$1-0004$

Błaszczyk, K., Wilczak, J., Harasym, J., Gudej, S., Suchecka, D., Królikowski, T., Lange, E., \& Gromadzka-Ostrowska, J. (2015). Impact of low and high molecular weight oat beta-glucan on oxidative stress and antioxidant defense in spleen of rats with LPS induced enteritis. Food Hydrocolloids, 51, 272-280. https://doi.org/ 10.1016/j.foodhyd.2015.05.025

Chu, Y. F., Wise, M. L., Gulvady, A. A., Chang, T., Kendra, D. F., JanWillem Van Klinken, B., et al. (2013). In vitro antioxidant capacity and anti-inflammatory activity of seven common oats. Food Chemistry, 139(1-4), 426-431. https://doi.org/10.1016/j. foodchem.2013.01.104 
Dar, B. N., \& Sharma, S. (2011). Total phenolic content of cereal brans using conventional and microwave assisted extraction. American Journal of Food Technology, 6(12), 1045-1053. https://doi.org/10. 3923/ajft.2011.1045.1053

Decker, E. A., Rose, D. J., \& Stewart, D. (2014). Processing of oats and the impact of processing operations on nutrition and health benefits. British Journal of Nutrition, 112(S2), S58-S64. https://doi.org/10. 1017/S000711451400227X

European Food Safety Authority (EFSA). (2010). Scientific Opinion on the substantiation of a health claim related to oat beta-glucan and lowering blood cholesterol and reduced risk of (coronary) heart disease pursuant to Article 14 of Regulation (EC). EFSA Journal,

European Food Safety Authority (EFSA). (2011). Scientific Opinion on the substantiation of health claims related to beta-glucans from oats and barley and maintenance of normal blood LDL-cholesterol concentrations. EFSA Journal, 9(6), 2207.

EFSA Panel on Dietetic Products, N. and A. (NDA). (2011). Scientific Opinion on the substantiation of health claims related to oat and barley grain fibre and increase in faecal bulk ( ID 819,822 ) pursuant to. EFSA Journal, 9(6), 2249, DOI: https://doi.org/10. 2903/j.efsa.2011.2249.

Ekezie, F. G. C., Sun, D. W., \& Cheng, J. H. (2017). Acceleration of microwave-assisted extraction processes of food components by integrating technologies and applying emerging solvents: a review of latest developments. Trends in Food Science and Technology, 67, 160-172. https://doi.org/10.1016/j.tifs.2017.06.006

Gates, F. K., Sontag-Strohm, T., Stoddard, F. L., Dobraszczyk, B. J., \& Salovaara, H. (2008). Interaction of heat-moisture conditions and physical properties in oat processing: II. Flake quality. Journal of Cereal Science, 48(2), 288-293. https://doi.org/10.1016/j.jcs.2007. 09.009

Girardet, N., \& Webster, F. H. (2011). Oat milling: specifications, storage, and processing. Oats: chemistry and technology: Second Edition.

Guo, Q., Sun, D.-W., Cheng, J.-H., \& Han, Z. (2017). Microwave processing techniques and their recent applications in the food industry. Trends in Food Science \& Technology, 67, 236-247. https://doi.org/ 10.1016/j.tifs.2017.07.007

Harasym, J., \& Oledzki, R. (2014). Effect of fruit and vegetable antioxidants on total antioxidant capacity of blood plasma. Nutrition, 30(5), 511-517. https://doi.org/10.1016/j.nut.2013.08.019

Hitayezu, R., Baakdah, M. M., Kinnin, J., Henderson, K., \& Tsopmo, A. (2015). Antioxidant activity, avenanthramide and phenolic acid contents of oat milling fractions. Journal of Cereal Science, 63, 35-40. https://doi.org/10.1016/j.jcs.2015.02.005

Itagi, H. N., Rao, B. V. R. S., Jayadeep, P. A., \& Singh, V. (2012). Functional and antioxidant properties of ready-to-eat flakes from various cereals including sorghum and millets. Quality Assurance and Safety of Crops \& Foods, 4(3), 126-133. https://doi.org/10. 1111/j.1757-837X.2012.00136.x

Korzeniowska-Ginter, R., \& Kamińska, A. (2014). Wiedza Konsumentów Na Temat Prozdrowotnych. Zeszyty Naukowe Akademii Morskiej w Gdyni, (86), 124-132.

Masisi, K., Beta, T., \& Moghadasian, M. H. (2016). Antioxidant properties of diverse cereal grains: a review on in vitro and in vivo studies. Food Chemistry, 196, 90-97. https://doi.org/10.1016/j.foodchem. 2015.09.021

Ozturk, O. K., \& Takhar, P. S. (2017). Stress relaxation behavior of oat flakes. Journal of Cereal Science, 77, 84-89. https://doi.org/10. 1016/j.jcs.2017.08.005
Pérez-Jiménez, J., \& Saura-Calixto, F. (2005). Literature data may underestimate the actual antioxidant capacity of cereals. Journal of Agricultural and Food Chemistry, 53(12), 5036-5040. https://doi. org/10.1021/jf050049u

Pérez-Quirce, S., Ronda, F., Lazaridou, A., \& Biliaderis, C. G. (2017). Effect of microwave radiation pretreatment of Rice flour on glutenfree breadmaking and molecular size of $\beta$-glucans in the fortified breads. Food and Bioprocess Technology, 10(8), 1412-1421. https:// doi.org/10.1007/s11947-017-1910-7

Pérez-Quirce, S., Ronda, F., Melendre, C., Lazaridou, A., \& Biliaderis, C. G. (2016). Inactivation of endogenous rice flour $\beta$-glucanase by microwave radiation and impact on physico-chemical properties of the treated flour. Food and Bioprocess Technology, 9(9), 15621573. https://doi.org/10.1007/s11947-016-1741-y

Prior, L. R., Wu, X., \& Schaich, K. (2005). Standardized methods for the determination of antioxidant capacity and phenolics in foods and dietary supplements. Journal of Agricultural and Food Chemistry, 53(10), 4290-4302. https://doi.org/10.1021/jf0502698

Qian, K., Ren, C., \& Li, Z. (2009). An investigation on pretreatments for inactivation of lipase in naked oat kernels using microwave heating. Journal of Food Engineering, 95(2), 280-284.

Rzedzicki, Z., \& Wirkijowska, A. (2008). Charakterystyka składu chemicznego przetworów jęczmiennych ze szczególnym uwzględnieniem składu frakcyjnego błonnika pokarmowego. ŻNTJ, 1(56), 52-64.

Rzedzicki, Z. (2006). Charakterystyka składu chemicznego wybranych przetworów owsianych. IHAR Bulletin, 239, 269-280.

Sang, S., \& Chu, Y. F. (2017). Whole grain oats, more than just a fiber: role of unique phytochemicals. Molecular Nutrition and Food Research, 61(7), 1-12. https://doi.org/10.1002/mnfr.201600715

Shah, A., Gani, A., Masoodi, F. A., Wani, S. M., \& Ashwar, B. A. (2017). Structural, rheological and nutraceutical potential of $\beta$-glucan from barley and oat. Bioactive Carbohydrates and Dietary Fibre, 10, 10 16. https://doi.org/10.1016/j.bcdf.2017.03.001

Stevenson, D. G., Inglett, G. E., Chen, D., Biswas, A., Eller, F. J., \& Evangelista, R. L. (2008). Phenolic content and antioxidant capacity of supercritical carbon dioxide-treated and air-classified oat bran concentrate microwave-irradiated in water or ethanol at varying temperatures. Food Chemistry, 108(1), 23-30. https://doi.org/10.1016/j. foodchem.2007.08.060

Suchecka, D., Harasym, J., Wilczak, J., \& Gromadzka-Ostrowska, J. (2016). Hepato- and gastro- protective activity of purified oat $1-3$, $1-4-\beta$-D-glucans of different molecular weight. International Journal of Biological Macromolecules, 91, 1177-1185. https://doi. org/10.1016/j.ijbiomac.2016.06.062

Wang, Y.-J., Maina, N. H., Ekholm, P., Lampi, A.-M., \& Sontag-Strohm, T. (2017). Retardation of oxidation by residual phytate in purified cereal $\beta$-glucans. Food Hydrocolloids, 66, 161-167. https://doi.org/ 10.1016/j.foodhyd.2016.11.019

Yiu, S.H., Weisz, J., \& W. P. J. (1991). Comparison of the effects of microwave and conventional cooking on starch and beta-glucan in rolled oats. Cereal Chemistry, 68(4), 372-375.

Zieliński, H., \& Kozłowska, H. (2000). Antioxidant activity and total phenolics in selected cereal grains and their different morphological fractions. Journal of Agricultural and Food Chemistry, 48(6), 20082016. https://doi.org/10.1021/j9990619o 